\title{
Esophagobronchial fistula closed by a cardiac septal occluder device
}

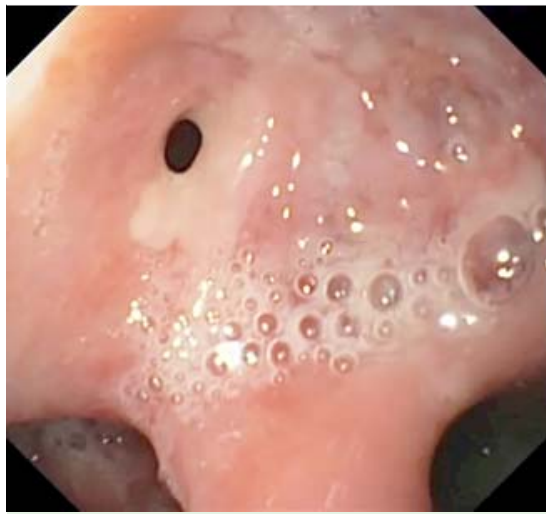

Fig. 1 Esophageal view of the fistulous orifice.

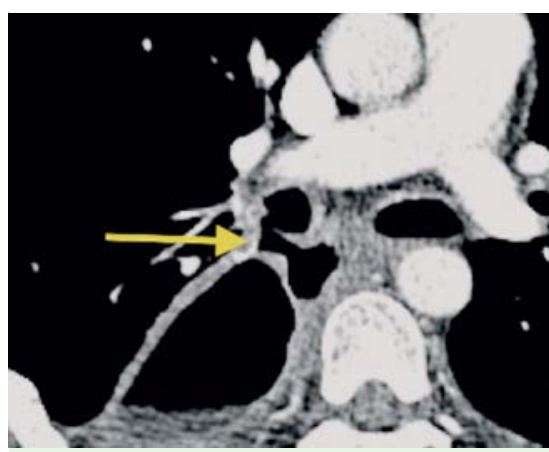

Fig. 2 Computed tomography (CT) scan image showing the fistula between the left bronchus and esophagus.

Esophageal-respiratory tract fistulas are rare but life-threatening conditions [1]. They may be congenital or secondary to esophageal and bronchogenic neoplasms, radiotherapy, or surgery. Currently, there is a changing paradigm for their management with surgery being replaced by conservative approaches including endoscopic therapy [2]. In fact, fully covered self-expandable metal stents (SEMSs) are currently the preferred therapeutic option; however, their clinical success rate is still poor and the rate of fistula reopening remains high $[1,2]$. This has led to the appearance of therapeutic alternatives, such as the use of cardiac septal closure -devices and others [3-5].

We present the case of a 51-year-old man who had undergone prior chemoradiotherapy and esophagectomy for esophageal cancer. During follow-up, the patient developed mediastinal and brain metastases, as well as a severe cough and respiratory infections due to an esophagobron-

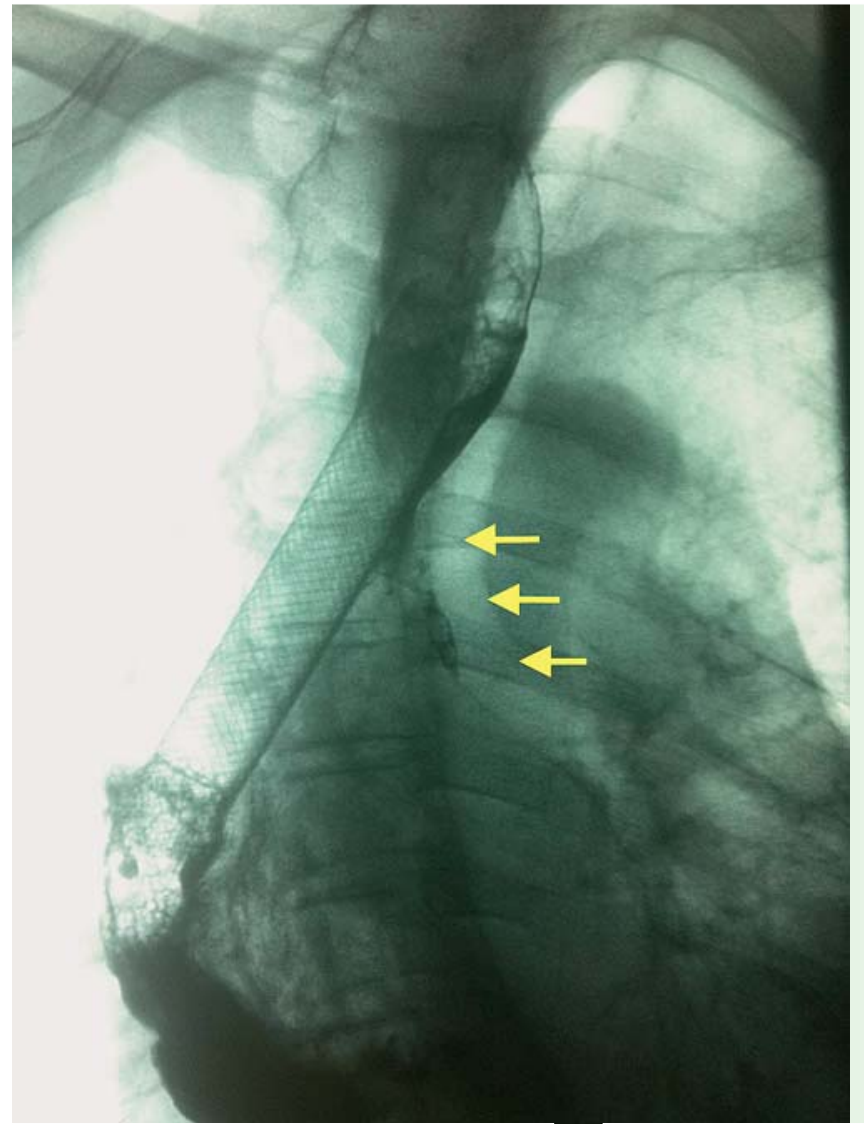

Fig. 3 Radiographic image showing a covered self-expandable metal stent (SEMS) in position, which proved to be an unsuccessful treatment.

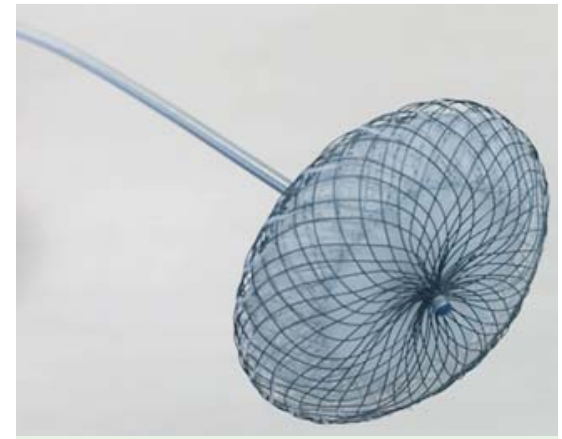

Fig. 4 The Amplatzer septal occluder.

chial fistula ( $\bullet$ Fig. 1 and $\bullet$ Fig. 2). It was decided not to perform surgery but conventional endoscopic approaches were unsuccessful ( $\bullet$ Fig.3). We therefore decided to use the Amplatzer septal occluder (St. Jude Medical, Plymouth, Minnesota, USA), a nitinol device commonly used to close cardiac septal defects ( $\bullet$ Fig.4). An upper gastrointestinal endoscopy was performed, which showed a 5-mm fistu-

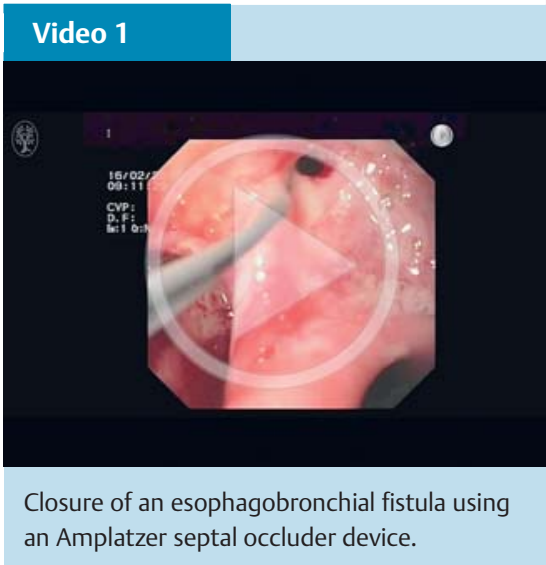

lous orifice located at the esophagogastric anastomosis. From the esophageal side, a guidewire was inserted through the fistula into the airway and then captured with a forceps to take it back out of the patient, in order to facilitate device positioning ( $\bullet$ Video 1). A 5-Fr catheter was then introduced and subsequently the occluder was released, firstly on the airway side and then on the esophageal side under 

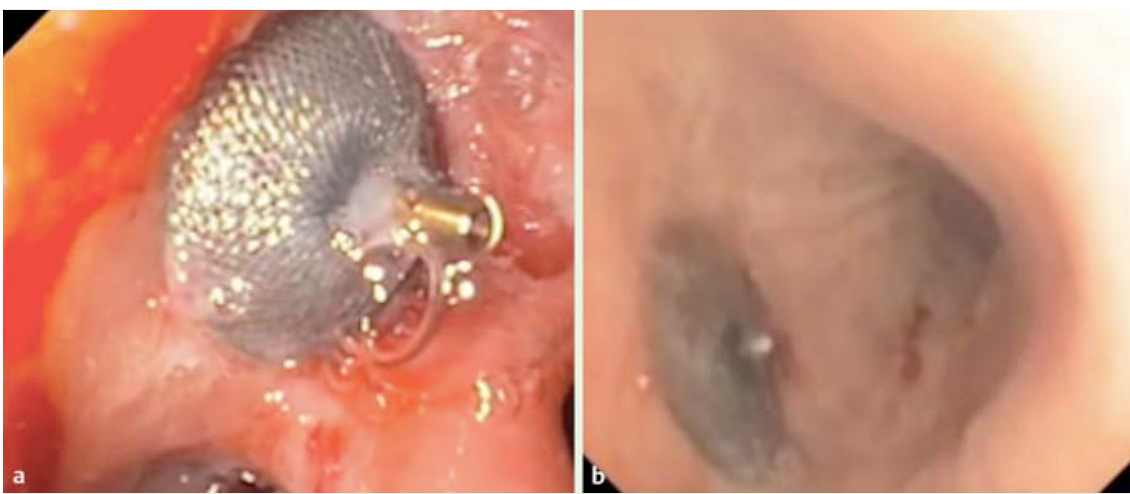

Fig. 5 Views of the occluder device following insertion into the fistula: $\mathbf{a}$ from the esophagus; $\mathbf{b}$ from the bronchus.

endoscopic control ( $\bullet$ Fig. 5 and $\bullet$ Fig. 6 ). The procedure was safely completed. The patient experienced a significant improvement in his respiratory symptoms. A second occluder was inserted 4 weeks later because of the development of a new fistula and remained in place until his death 9 months later from progressive brain metastases.

Endoscopy_UCTN_Code_TTT_1AO_2AI

\section{Competing interests: None}

\section{Ignacio Fernandez-Urien ${ }^{1}$, Roman Lezaun², Maria Hernández ${ }^{3}$, Baltasar Lainez $^{2}$, Catia Leitão ${ }^{4}$, Juan Vila ${ }^{1}$}

${ }^{1}$ Department of Gastroenterology, CHN, Pamplona, Spain

2 Department of Cardiology, CHN, Pamplona, Spain

${ }^{3}$ Department of Neumology, CHN, Pamplona, Spain

${ }^{4}$ Department of Gastroenterology, Hospital Amato-Lusitano, Castelo Branco, Portugal

\section{References}

1 Shin JH, Song HY, Ko GY et al. Esophagorespiratory fistula: long-term results of palliative treatment with covered expandable metallic stents in 61 patients. Radiology 2004; 232: $252-259$

2 Sharma P, Kozarek R. Role of esophageal stents in benign and malignant diseases. Am J Gastroenterol 2010; 105: 258-273

3 Repici A, Presbitero P, Carlino A et al. First human case of esophagus-tracheal fistula closure by using a cardiac septal occluder (with video). Gastrointest Endosc 2010; 71: 867-869

4 Khamaysi I, Suissa A, Yassin Ket al. Closure of a persistent esophagopleural fistula using an over-the-scope clipping device. Endoscopy 2013; 45 (Suppl. 02): E29-E30

5 Rodriguez-Lago I, Schroeven M, Rodenstein D et al. Endoscopic closure of tracheoesophageal fistula with submucosal dissection and a biosynthetic mesh. Endoscopy 2015; 47 (Suppl. 01): E312-E313

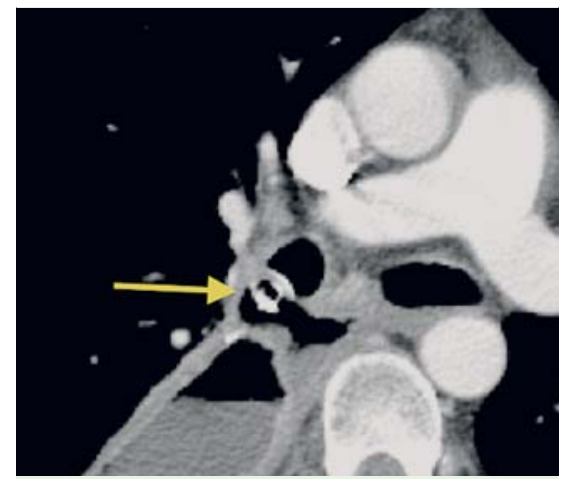

Fig. 6 Computed tomography (CT) scan image showing the correctly positioned occluder device.

\section{Bibliography}

Dol http://dx.doi.org/

10.1055/s-0042-112974

Endoscopy 2016; 48: E289-E290

(c) Georg Thieme Verlag KG

Stuttgart · New York

ISSN 0013-726X

\section{Corresponding author}

Ignacio Fernandez-Urien, MD, PhD

Department of Gastroenterology

CHN Pamplona (España)

c/ Irunlarrea 3

31008 Pamplona

Navarra

Spain

ifurien@yahoo.es 